\title{
Our clinic's first experience with HoLEP
}

\author{
(1) Serkan Dogan, (1) Kenan Yigit Yildiz \\ Department of Urology, Turkiye Yuksek Ihtisas Training and Research Hospital, Ankara, Turkey
}

\begin{abstract}
OBJECTIVE: The present study reports a retrospective evaluation of the first Holmium laser prostate enucleation (HoLEP) cases and their results in our clinic.

METHODS: Twenty four patients who underwent HoLEP surgery between April 2017 and November 2017 were evaluated for demographic characteristics, duration of operation, amount of hemorrhage, amount of energy used, tissue weight removed, catheterization time and complications. IPSS and uroflowmetry results were compared before and after the surgery.

RESULTS: Patients with hemoglobin, IPSS, uroflowmetry, and voiding speeds (Qmean, Qmax) were compared before and after the surgery. There was a significant difference in IPSS, Qmean and hemoglobin values but not in Qmax, statistically. Our complications rates were correlated with the literature.

CONCLUSION: HoLEP stands out as a surgical method that can be applied with high confidence in the treatment of benign prostatic hyperplasia and it has similar functional results to gold standard surgeries, causes fewer complications, improves patient comfort due to short catheterization and hospitalization and is more advantageous regarding cost.
\end{abstract}

Keywords: Benign prostate hyperplasia; enucleation; holmium laser.

Cite this article as: Dogan S, Yildiz KK. Our clinic's first experience with HoLEP. North Clin Istanb 2019;6(4):355-360.

B enign prostate hyperplasia $(\mathrm{BPH})$ is one of the most common pathologies that affect male and has a prevalence of up to $50 \%$ in the sixth decade [1]. Transurethral prostate resection (TURP) is accepted as the gold standard in the endoscopic treatment of $\mathrm{BPH}$ [2]. However, some alternative treatments have surfaced in recent years with the widespread use of laser in urology. One of them is a Holmium laser enucleation of the prostate (HoLEP) [3].

HoLEP was first performed by Gilling et al. [4] in 1995 not as enucleation but as resection. A few years later, the same team developed the enucleation method [5]. Over time, HoLEP has emerged in laser-implemented methods [6, 7]. According to the European Association of Urology (EAU) guidelines, while recommended as an alternative to TURP in patients with moderate lower urinary symptoms, it is also recommended as an alternative to prostatectomy in patients with $>80 \mathrm{ml}$ prostate volume in the same patient group [8]. HoLEP is especially recommended in patients undergoing anticoagulant treatment and/or at high cardiovascular risk. According to the American Urology Association (AUA) guidelines, it also holds a place in surgical treatment options in BPH, which causes less morbidity and had outcomes comparable to TRP, as well as mentioning its high learning curve and requirement of long-term follow-up results [9-13].

Although TURP is the most commonly performed in the surgical treatment of $\mathrm{BPH}$ and is accepted as the gold standard method, it also has complications, such as retention, urinary infection, hemorrhage, urethra stenosis, need for repeated operation, retrograde ejaculation, and TUR syndrome as well as long catheterization and hospitalization period [14]. According to many studies, HoLEP 
has fewer complications than TURP and requires shorter hospitalization and catheterization period [7].

HoLEP is an increasingly performed surgical method. However, HoLEP have a longer learning curve compared to some other endoscopic prostate operations $[15,16]$. Herein, we present our clinic's short-term outcomes of this operation with increasing popularity in our country.

\section{MATERIALS AND METHODS}

A total of 24 patients underwent HoLEP between April 2017 and November 2017 in our clinic. The demographic characteristics of age and prostate-specific antigen (PSA) levels of the patients were documented, while prostate volume was measured with transrectal ultrasound. The patients were evaluated according to operation lengths (enucleation length, morcellation length), amount of used energy, catheterization lengths, preoperative and postoperative Hgb levels, international prostate symptom scores (IPSS), and average (Qavg) and maximum (Qmax) flow rates. Operation-related complications were also documented. While postoperative hemoglobin levels were measured 24 hours after the operation, IPSS and uroflowmetry were evaluated three months postoperatively. This study was approved by the Ethics Committee of Türkiye Yüksek İhtisas Training and Research Hospital in February 2017 with the number 3713 .

For the HoLEP technique, the three-lobe technique was applied by the same surgeon in all patients. Storz brand working element was used. Lisa brand device was used for Holmium-YAG laser source at 80-watt power, 2.1-micron wavelength. Wolf brand Power Stick M4 $4.8 \mathrm{~mm}$ model was used as the morcellator. Enucleation was performed on prostate tissue; resection was not performed with a laser in any patient (Fig. 1). In one patient, due to morcellator defect, tissue discarded into the bladder was removed with plasmakinetic resection. Aside from this, an additional method was not applied in any other patient. All patients were inserted 20F 3 -way Foley urethral catheter. One patient was transferred to the cardiology clinic due to cardiovascular issues. Because the patient who underwent coronary angiography was monitored in intensive care, his catheter was not withdrawn because the cardiology specialists wanted to continue urethral catheterization in order to monitor urinary output.

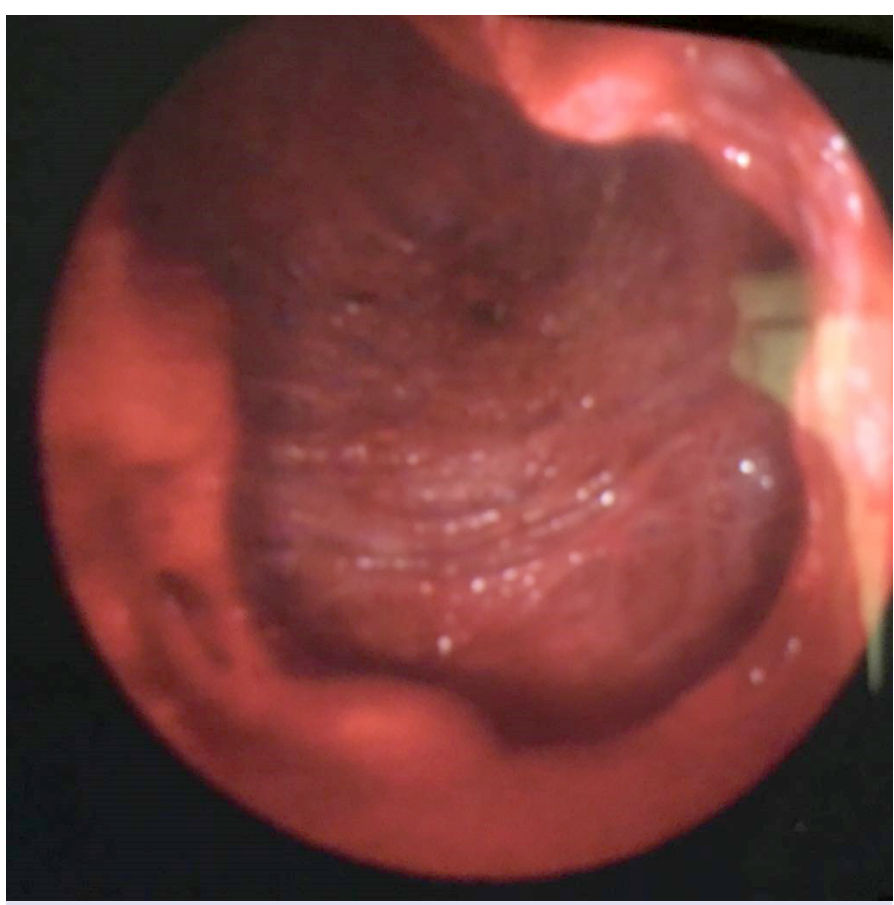

FIGURE 1. View of prostatic lodge following HoLEP.

\section{RESULTS}

The patients included in this study underwent primary prostate surgery. Demographic characteristics, such as age, prostate volume, and PSA level, along with surgical parameters, such as enucleation length, morcellation length, used energy, the weight of resected tissue, and urethral catheterization length of the patients, were evaluated, and statistical mean values were calculated (Table 1). Only one of the patients developed superficial bladder wall injury during intraoperative morcellation phase (4\%). There was no need for transfusion in any of our patients as well as no need for prolonged irrigation. None of the patients required re-catheterization following the

TABLE 1. Demographic and surgical characteristics of the patients

Age (years)

$65.6 \pm 4.4$

Prostate volume $(\mathrm{ml})$

$73.3 \pm 13.1$

PSA (ng/dl)

$2.98 \pm 1.38$

Enucleation length (min)

$107.9 \pm 17.2$

Morcellation length (min)

$37.3 \pm 8.1$

Used energy ( $\mathrm{j}$ )

Weight of resected tissue (gr)

$61522 \pm 6341$

Urethral catheterization length (hour)

$38.7 \pm 14.7$ 
withdrawal of the urethral catheter. While three patients had dysuria (12\%), two patients had transient urinary incontinence ( $8 \%)$. None of the patients developed urethral stenosis during our follow-up period.

Preoperative and postoperative hemoglobin, IPSS, and uroflowmetry flow rates (Qavg, Qmax) of the patients were compared. While these values were ordinal, as some preoperative and postoperative parameters were determined to have normal and non-normal distribution, a statistical comparison was assessed with two separate tests. Wilcoxon test was applied using median values, while $t$ test was applied in dependent groups using mean values. Both tests had similar results. Although there was a significant difference between preoperative and postoperative hemoglobin levels, IPSS, and Qavg, there was no significant difference between $\mathrm{Qmax}$ in both tests (Table 2).

\section{DISCUSSION}

Open prostatectomy and TURP are the most commonly used methods according to prostate size in the surgical treatment of bladder outlet obstruction due to $\mathrm{BPH}$ in elderly patients. However, both methods have a long list of complications [14, 17-19]. In search of an alternative to these treatments, the HoLEP method stands out with its levels of efficacy and reliability.

According to results of a meta-analysis comparing HoLEP and TURP that evaluated a total of six studies and 541 patients, 12-month postoperative data favored HoLEP regarding Qmax and IPSS. The same study found that HoLEP was also advantageous according to blood loss, transfusion need, catheterization length, and hospitalization length. However, statistical analysis favored TURP according to operation length and postoperative dysuria [20]. Another study that compared TURP and HoLEP, assigned patients to three groups according to prostate sizes and, concerning operation length, TURP length was shorter in the 40 gr and 40$80 \mathrm{gr}$ groups, and operation length was the same in the $>80$ gr group [21]. Gu M et al. [22] compared 72-month follow-up outcomes of plasmakinetic prostate resection and HoLEP in 280 patients and found that Qmax, decrease in PSA level, International Index of Erectile Function (IIEF) score, and need for retreatment was found in favor in HoLEP. Woo MJ et al. [23] compared results of TURP and HoLEP in 56 patients and six-month postoperative tests were in favor of HoLEP according to Qmax and post-void residual volume (PVR). In a study that distributed 144 patients into two equal homogeneous groups and compared TURP and HoLEP in $>60$ gr prostates, HoLEP was found advantageous regarding the amount of the resected tissue, amount of hemorrhage, development of hyponatremia, catheterization length, hospitalization length, and 12- and 24-month Qmax [24]. When both methods are evaluated according to long-term functional outcome, there are studies that show HoLEP has lower rates of urethral stenosis, independent of duration $[25,26]$.

Patrick Jones et al. [27] conducted a meta-analysis of studies that compared open prostatectomy and HoLEP, and while they found no difference in functional outcomes, open prostatectomy was found advantageous in terms of resected tissue amount and operation length. However, the amount of hemorrhage, catheteriza-

TABLE2. Comparison of the preoperative and postoperative parameters

\begin{tabular}{lccc} 
Dependent groups t-test & Preoperative & Postoperative & $P$ \\
\hline Hgb $(\mathrm{g} / \mathrm{dl})$ & $13.2 \pm 0.9$ & $12.9 \pm 0.8$ & 0.003 \\
IPSS & $26.5 \pm 2.2$ & $23.3 \pm 2.1$ & $<0.001$ \\
Qavg $(\mathrm{ml} / \mathrm{s})$ & $8.7 \pm 1.7$ & $9.6 \pm 2.0$ & $<0.001$ \\
Qmax $(\mathrm{ml} / \mathrm{s})$ & $14.1 \pm 2.4$ & $14.8 \pm 2.5$ & 0.069 \\
\hline Wilcoxon test & Preoperative & Postoperative & $\mathrm{P}$ \\
\hline Hgb $(\mathrm{g} / \mathrm{dl})$ & $13.3(11.5-15.1)$ & $12.9(10.9-14.5)$ & 0.003 \\
IPSS & $26.5(22-31)$ & $22(18-26)$ & $<0.001$ \\
Qavg $(\mathrm{ml} / \mathrm{s})$ & $8.2(6.8-13.1)$ & $9(7.5-14.5)$ & $<0.001$ \\
Qmax $(\mathrm{ml} / \mathrm{s})$ & $13.7(10.6-19.6)$ & $14.4(11.1-21.2)$ & 0.108
\end{tabular}


tion length, and hospitalization length were in favor of HoLEP. Richard Naspro et al. conducted a study on 80 patients (39 HoLEP/41 OP) and found no difference in regression of long-term disease-related symptoms, but also found that OP had better outcome according to bladder mucosal injury and dysuria. Outcomes of urinary retention were not found significant but were in favor of OP with a 5/2 patient ratio [28]. Elshal AM et al. investigated 91 HoLEP and 92 open prostatectomy patients and found that HoLEP was advantageous regarding transfusion need, catheterization length, and hospitalization length. Patients who underwent HoLEP were reported to have more additional comorbidities, while local wound infections were reported in some of the open prostatectomy patients. Additionally, HoLEP was more inexpensive (575/602 USD) but not found statistically significant [29].

Chen $\mathrm{H}$ et al. [30] presented a meta-analysis of three randomized controlled in which a total of 260 patients were evaluated, and found that blood loss, catheterization and hospitalization lengths were in favor of HoLEP, while operation length was in favor open prostatectomy. In the same publication, the findings showed that there was no significant difference regarding urethral stenosis, stress incontinence, need for transfusion, and repeated operation rates. While many studies found HoLEP to have longer operation length, a study by Ahyai et al. [31] found that TURP was statistically similar to the shorter open prostatectomy according to the amount of resected tissue within the allotted time. Although Hwang JC et al. reported that HoLEP was better than open prostatectomy and TURP operation regarding postoperative infection, another study by Shigemura et al. published in the same journal did not find HoLEP to be preferable in this subject. They attributed this to long operation length and surgical inexperience $[32,33]$. Andrea Salonia et al. performed a financial analysis in a study of 63 patients (34 HoLEP/29 OP) in which expenses were reported as 2356.50 and 2868.90 USD, respectively, and found that HoLEP was favorable [34]. In a meta-analysis with one of the largest number of patients, HoLEP, PVP, TURP, and open prostatectomy results were evaluated and found that HoLEP was more advantageous than TURP and PVP according to Qmax and IPSS results. This study had also indicated that HoLEP was the only method that did not require repeated operation within five years [7].

There are studies that report that HoLEP is more preferable in patients under anticoagulant treatment [35]. This has been attributed to laser being more successful in hemostasis, but studies are limited, which remained under-researched. EAU guidelines also indicate that HoLEP is recommended in this patient group. In a study that compared 160 patients under anticoagulant/antiaggregant treatment to 1558 patients who were not receiving any of these treatments, bladder irrigation length and hospitalization length was significantly longer in the treatment group patients. However, there was no significant difference in the decrease in hemoglobin levels and transfusion need [36]. Since the development of urinary retention depends on obstruction operations due to $\mathrm{BPH}$, various studies that investigated the reliability of HoLEP indicated that functional outcomes were the same in both patients that developed and did not develop postoperative recurrent retention [37, 38]. Although HoLEP was determined to be reliably performed in patients with bladder stones among pathologies requiring surgical treatment, the number of studies is limited [39], which should be researched.

In a meta-analysis consisting of 27 studies by Li Wang et al., comparisons of results of laser methods used in endoscopic prostate surgery and TURP were investigated. According to IPSS, Holmium laser resection had the best outcomes six months postoperatively, while HoLEP had the best outcomes 12 months postoperatively. For Qmax, HoLEP had the best results both in the sixth and twelfth month [40]. Kim KS et al. [41] compared PVP and HoLEP in 338 patients and only found that firstmonth postoperative IPSS score favored HoLEP and no results favoring PVP. In another laser comparison study, thulium laser enucleation and HoLEP had similar efficacy and reliability results [42]. Elshal et al. compared Greenlight photoselective vaporization and HoLEP in two separate studies and found that HoLEP was superior regarding the operation, catheterization, and hospitalization lengths, as well as IPSS, uroflowmetry results, PVR, postoperative prostate size, and costs $[43,44]$.

Although complications of HoLEP surgery have been reported in separate studies, the most comprehensive study was published by Hemendra et al. In their study, the complications of 280 patients were evaluated, and capsular perforation was reported as the most common perioperative complication (9.6\%) followed by superficial bladder mucosal injury and ureteric orifice injury. The same study listed postoperative complications according to frequency, transient urinary incontinence 
(10.7\%), re-catheterization, urinary system infection, and meatal dilation [45].

In our study, although there was no significant difference in IPSS and Qavg results, a significant decrease in $\mathrm{Hgb}$ level was a separate subject of interest. We attribute this situation to that our hospital is one of the largest health institutions in our country regarding cardiology and cardiovascular surgery, and that the number of patients receiving anticoagulant and antiaggregant treatment in both clinical practices and as patients included in this study may be in excess. Although different surgical methods were compared in our study, considering routine practice, we believe that other methods to be more advantageous concerning urethral catheterization and therefore hospitalization length.

\section{Conclusion}

HoLEP stands out as a relatively reliable and cost-effective surgical method in the treatment of benign prostate hyperplasia, with functional results similar to gold standard operations but with fewer complications and shorter catheterization and hospitalization lengths contributing to increased patient comfort. We believe this method, an alternative to TURP and OP for experienced surgeons, will assume the position in guidelines as the gold standard in the future.

Ethics Committee Approval: This study was approved by the ethics committee of Türkiye Yüksek İhtisas Training and Research Hospital in February 2017 with the number 3713.

Conflict of Interest: No conflict of interest was declared by the authors.

Financial Disclosure: The authors declared that this study has received no financial support.

Authorship Contributions: Concept - SD; Design - SD; Supervision - SD; Materials - SD, KYY; Data collection and/or processing - SD, KYY; Analysis and/or interpretation - SD; Writing - SD; Critical review - SD.

\section{REFERENCES}

1. Patel ND, Parsons JK. Epidemiology and etiology of benign prostatic hyperplasia and bladder outlet obstruction. Indian J Urol 2014;30:1706. [CrossRef]

2. AUA Practice Guidelines Committee. AUA guideline on management of benign prostatic hyperplasia (2003). Chapter 1 : Diagnosis and treatment recommendations. J Urol 2003;170:530-47. [CrossRef]

3. Kuntz RM. Current role of lasers in the treatment of benign prostatic hyperplasia (BPH). Eur Urol 2006;49:961-9. [CrossRef]

4. Gilling PJ, Cass CB, Cresswell MD, Fraundorfer MR. Holmium laser resection of the prostate: preliminary results of a new method for the treatment of benign prostatic hyperplasia. Urology 1996;47:48-51.

5. Gilling PJ, Kennett K, Das AK, Thompson D, Fraundorfer MR. Holmium laser enucleation of the prostate (HoLEP) combined with transurethral tissue morcellation: an update on the early clinical experience. J Endourol 1998;12:457-9. [CrossRef]

6. Elzayat EA, Habib EI, Elhilali MM. Holmium laser enucleation of the prostate: a size-independent new "gold standard". Urology 2005;66:108-13.

7. Michalak J, Tzou D, Funk J. HoLEP: the gold standard for the surgical management of BPH in the 21(st) Century. Am J Clin Exp Urol 2015;3:36-42.

8. Oelke M, Bachmann A, Descazeaud A, Emberton M, Gravas S, Michel $\mathrm{MC}$, et al. EAU guidelines on the treatment and follow-up of non-neurogenic male lower urinary tract symptoms including benign prostatic obstruction. Eur Urol 2013;64:118-40. [CrossRef]

9. Hochreiter WW, Thalmann GN, Burkhard FC, Studer UE. Holmium laser enucleation of the prostate combined with electrocautery resection: the mushroom technique. J Urol 2002;168:1470-4. [CrossRef]

10. Hurle R, Vavassori I, Piccinelli A, Manzetti A, Valenti S, Vismara A. Holmium laser enucleation of the prostate combined with mechanical morcellation in 155 patients with benign prostatic hyperplasia. Urology 2002;60:449-53. [CrossRef]

11. Kuntz RM, Lehrich K. Transurethral holmium laser enucleation versus transvesical open enucleation for prostate adenoma greater than 100 gm.:: a randomized prospective trial of 120 patients. J Urol 2002;168:1465-9. [CrossRef]

12. Das A, Kennett K, Fraundorfer M, Gilling P. Holmium laser resection of the prostate (HoLRP): 2-year follow-up data. Tech Urol 2001;7:252-5.

13. Gilling P, Kennett K, Fraundorfer MR. Holmium laser resection v transurethral resection of the prostate: results of a randomized trial with 2 years of follow-up. J Endourol 2000;14:757-60. [CrossRef]

14. Rassweiler J, Teber D, Kuntz R, Hofmann R. Complications of Trans urethral Resection of the Prostate (TURP) Incidence, Management, and Prevention. Eur Urol 2006;50:969-79. [CrossRef]

15. Brunckhorst O, Ahmed K, Nehikhare O, Marra G, Challacombe B, Popert R. Evaluation of the Learning Curve for Holmium Laser Enucleation of the Prostate Using Multiple Outcome Measures.Urology 2015;86:824-9. [CrossRef]

16. Peyronnet B, Robert G, Comat V, Rouprêt M, Gomez-Sancha F, Cornu $\mathrm{JN}$, et al. Learning curves and perioperative outcomes after endoscopic enucleation of the prostate: a comparison between GreenLight 532-nm and holmium lasers. World J Urol 2017;35:973-83. [CrossRef]

17. Kusljic S, Aneja J, Manias E. Incidence of complications in men undergoing transurethral resection of the prostate. Collegian 2017;24:3-9.

18. Cornu JN, Herrmann T, Traxer O, Matlaga B. Prevention and Management Following Complications from Endourology Procedures. Eur Urol Focus 2016;2:49-59. [CrossRef]

19. McCullough TC, Heldwein FL, Soon SJ, Galiano M, Barret E, Cathelineau $\mathrm{X}$, et al. Laparoscopic versus open simple prostatectomy: an evaluation of morbidity. J Endourol 2009;23:129-33. [CrossRef]

20. Yin L, Teng J, Huang CJ, Zhang X, Xu D. Holmium laser enucleation of the prostate versus transurethral resection of the prostate: a systematic review and meta-analysis of randomized controlled trials. J Endourol 2013;27:604-11. [CrossRef]

21. Lee MH, Yang HJ, Kim DS, Lee CH, Jeon YS. Holmium laser enucleation of the prostate is effective in the treatment of symptomatic benign prostatic hyperplasia of any size including a small prostate. Korean J 
Urol 2014;55:737-41. [CrossRef]

22. Gu M, Chen YB, Liu C, Wan X, Cai ZK, Chen Q, et al. Comparison of Holmium Laser Enucleation and Plasmakinetic Resection of Prostate: A Randomized Trial with 72-Month Follow-Up. J Endourol 2018;32:139-43. [CrossRef]

23. Woo MJ, Ha YS, Lee JN, Kim BS, Kim HT, Yoo ES. Comparison of Surgical Outcomes Between Holmium Laser Enucleation and Transurethral Resection of the Prostate in Patients With Detrusor Underactivity. Int Neurourol J 2017;21:46-52. [CrossRef]

24. Jhanwar A, Sinha RJ, Bansal A, Prakash G, Singh K, Singh V. Outcomes of transurethral resection and holmium laser enucleation in more than $60 \mathrm{~g}$ of prostate: A prospective randomized study.Urol Ann 2017;9:45-50. [CrossRef]

25. Montorsi F, Naspro R, Salonia A, Suardi N, Briganti A, Zanoni M, et al. Holmium laser enucleation versus transurethral resection of the prostate: results from a 2-center prospective randomized trial in patients with obstructive benign prostatic hyperplasia. J Urol 2008;179:S8790. [CrossRef]

26. Wilson LC, Gilling PJ, Williams A, Kennett KM, Frampton CM, Westenberg AM, et al. A randomised trial comparing holmium laser enucleation versus transurethral resection in the treatment of prostates larger than 40 grams: results at 2 years. Eur Urol 2006;50:569-73.

27. Jones P, Alzweri L, Rai BP, Somani BK, Bates C, Aboumarzouk OM. Holmium laser enucleation versus simple prostatectomy for treating large prostates: Results of a systematic review and meta-analysis. Arab J Urol 2016;14:50-8. [CrossRef]

28. Naspro R, Suardi N, Salonia A, Scattoni V, Guazzoni G, Colombo R, et al. Holmium laser enucleation of the prostate versus open prostatectomy for prostates $>70 \mathrm{~g}: 24$-month follow-up. Eur Urol 2006;50:5638. [CrossRef]

29. Elshal AM, Mekkawy R, Laymon M, Barakat TS, Elsaadany MM, ElAssmy A, et al. Holmium laser enucleation of the prostate for treatment for large-sized benign prostate hyperplasia; is it a realistic endourologic alternative in developing country? World J Urol 2016;34:399-405.

30. Chen H, Tang P, Ou R, Deng X, Xie K. Holmium laser enucleation versus open prostatectomy for large volume benign prostatic hyperplasia: a meta-analysis of the therapeutic effect and safety. Nan Fang Yi Ke Da Xue Xue Bao 2012;32:882-5.

31. Ahyai SA, Gilling P, Kaplan SA, Kuntz RM, Madersbacher S, Montorsi F, et al. Meta-analysis of functional outcomes and complications following transurethral procedures for lower urinary tract symptoms resulting from benign prostatic enlargement. Eur Urol 2010;58:38497. [CrossRef]

32. Hwang JC, Park SM, Lee JB. Holmium laser enucleation of the prostate for benign prostatic hyperplasia: effectiveness, safety, and overcoming of the learning curve. Korean J Urol 2010;51:619-24. [CrossRef]

33. Shigemura K, Tanaka K, Haraguchi T, Yamamichi F, Muramaki M,
Miyake $\mathrm{H}$, et al. Postoperative infectious complications in our early experience with holmium laser enucleation of the prostate for benign prostatic hyperplasia. Korean J Urol 2013;54:189-93. [CrossRef]

34. Salonia A, Suardi N, Naspro R, Mazzoccoli B, Zanni G, Gallina A, et al. Holmium laser enucleation versus open prostatectomy for benign prostatic hyperplasia: an inpatient cost analysis. Urology 2006;68:3026. [CrossRef]

35. Rivera M, Krambeck A, Lingeman J. Holmium Laser Enucleation of the Prostate in Patients Requiring Anticoagulation. Curr Urol Rep 2017;18:77. [CrossRef]

36. El Tayeb MM, Jacob JM, Bhojani N, Bammerlin E, Lingeman JE. Holmium Laser Enucleation of the Prostate in Patients Requiring Anticoagulation. J Endourol 2016;30:805-9. [CrossRef]

37. Peterson MD, Matlaga BR, Kim SC, Kuo RL, Soergel TM, Watkins $\mathrm{SL}$, et al. Holmium laser enucleation of the prostate for men with urinary retention. J Urol 2005;174:998-1001. [CrossRef]

38. Johnsen NV, Kammann TJ, Marien T, Pickens RB, Miller NL. Comparison of holmium laser prostate enucleation outcomes in patients with or without preoperative urinary retention. J Urol 2016;195:10216. [CrossRef]

39. Tangpaitoon T, Marien T, Kadihasanoglu M, Miller NL. Does Cystolitholapaxy at the Time of Holmium Laser Enucleation of the Prostate Affect Outcomes? Urology 2017;99:192-6. [CrossRef]

40. Wang L, Yu QY, Liu Y, Zhu ZL, Huang YW, Li K. Efficacy and Safety of Laser Surgery and Transurethral Resection of the Prostate for Treating Benign Prostate Hyperplasia: a Network Meta-analysis. Asian Pac J Cancer Prev 2016;17:4281-8.

41. Kim KS, Choi JB, Bae WJ, Kim SJ, Cho HJ, Hong SH, et al. Comparison of Photoselective Vaporization versus Holmium Laser Enucleation for Treatment of Benign Prostate Hyperplasia in a Small Prostate Volume. PLoS One 2016;11:e0156133. [CrossRef]

42. Hong K, Liu YQ, Lu J, Xiao CL, Huang Y, Ma LL. Efficacy and safety of 120-W thulium:yttrium-aluminum-garnet vapoenucleation of prostates compared with holmium laser enucleation of prostates for benign prostatic hyperplasia. Chin Med J (Engl) 2015;128:884-9.

43. Elshal AM, Elkoushy MA, El-Nahas AR, Shoma AM, Nabeeh A, Carrier S, et al. GreenLight ${ }^{\mathrm{TM}}$ laser (XPS) photoselective vapo-enucleation versus holmium laser enucleation of the prostate for the treatment of symptomatic benign prostatic hyperplasia: a randomized controlled study. J Urol 2015;193:927-34. [CrossRef]

44. Elshal AM, Elmansy HM, Elhilali MM. Two laser ablation techniques for a prostate less than $60 \mathrm{~mL}$ : lessons learned 70 months after a randomized controlled trial. Urology 2013;82:416-22. [CrossRef]

45. Shah HN, Mahajan AP, Hegde SS, Bansal MB. Peri-operative complications of holmium laser enucleation of the prostate: experience in the first 280 patients, and a review of literature. BJU Int 2007;100:94-101. 